\title{
Developing students' cognitive and communicative skills when learning foreign languages
}

\author{
Helena Tsoupikova ${ }^{1}$, Margarita Tsyguleva ${ }^{1}$, and Maria Fedorova ${ }^{2, *}$ \\ ${ }^{1}$ Siberian State Automobile and Highway University, Foreign Languages Department, 644080 Omsk, Russia \\ ${ }^{2}$ Omsk State Technical University, Foreign Languages Department, 644050 Omsk, Russia
}

\begin{abstract}
The article is devoted to the problem of forming and improving students' cognitive skills in connection with development of communicative skills. The aim of the article is to study the effects of designing supporting schemes of different types on development of students' cognitive and communicative skills in the process of learning a foreign language. The authors summarized research findings on regularities of foreign language learning by university students and revealed conditions of enhancing the effectiveness of this process. The authors have justified the necessity and appropriateness of supporting schemes application when teaching foreign languages that are analogues of inner speech universal subject codes. The authors came to the conclusion that one of the most efficient ways to form and develop students' cognitive and communicative skills is to involve them in self-education, provide them with an appropriate algorithm of conscious and independent work with information, with each stage being constantly self-controlled.
\end{abstract}

\section{Introduction}

Modern scientific and technical conditions have changed a lot. Due to the rapid technological advance, time for developing new technologies has been reduced significantly and the amount of knowledge to be absorbed has greatly increased. These new features of the professional activities set new objectives for the system of professional education:

- $\quad$ to develop a new professional training assessment system, with the qualitative criteria for assessing acquired knowledge, skills, and abilities in terms of their timely application and rapid extraction from memory as well as the speed of orientation in the training task statement being included;

- to take into account the necessity of developing flexibility of professional thinking, mobility in solving professional problems;

- to include tasks aimed at cultivating students' creative abilities into the system of professional training;

- to form and develop students' skills of adequate response to incoming new information with simultaneous determination of its truthfulness, reliability and applicability in different professional conditions.

To solve all the tasks listed above students should obtain developed cognitive skills.

The priority strategy of education should be changed, with the main attention of the teacher being focused on providing the students with the ways and means of independent work with information [1]. Developing students' cognitive skills and abilities, including their ability to follow up the intellectual operations and stages of processing information, to conduct sound selfassessment and self-control using special algorithms, can greatly contribute to this process. Thus, the aim of the article is to present organization of student's work that is classified as an intelligent and creative one in a special way.

Intellectual and creative activity in comparison with an ordinary learning activity aimed at absorbing knowledge and skills presupposes their independent and creative transformation and application [2]. Such an activity orients students towards the semantic sphere, reflection, self-knowledge, stimulates them to be an actor $[3,4,5,6]$. It ensures the continuity of learning and social activities, prepares students for entering the professional sphere, and shows them prospects of constructive selfaffirmation and professional self-realization [7].

\section{A notion of "cognition in training"}

To provide cognition of the learning process is the main task of a teacher who works on the basis of a cognitive approach. The basic concepts of such a pedagogical activity are:

- Cognition. It is evident that any training is characterized by cognition, no matter if it is specially organized or accidental. But in this case, cognition presupposes organization of the learning process in such a way that cognitive activity is performed with greater efficiency and under given conditions [8], with all the stages of achieving the learning goals as well as clear identification of the scope of applying the knowledge gained being taken into account;

* Corresponding author: sidorova_ma79@mail.ru 
- $\quad$ Cognitive activity and its stages. Cognitive activity in modern education cannot be performed and organized without regard to the peculiarities of information processing in the human psyche. Processes of information transformation can be undertaken both sequentially and simultaneously. Information is altered at every stage of these processes: it is coded, some features are identified, then it is filtered, recognized, comprehended, a decision is made, a response is formed. Application of such an approach allows building a model of a mental process under investigation which consists of hypothetic blocks which are connected sequentially or simultaneously and perform certain functions. Sequential stages of processing information into personal knowledge realized by students can be called stages of cognitive activity $[9,10,11,12]$;

- Cognitive skills. We consider cognitive skills as modes of actions with learning information used by students at any stage of its transformation into knowledge.

Due to the cognitive approach which takes into account processes of constructing conceptual systems and using various types of knowledge, methodological systems (teaching and learning strategies are built) are developed and tested in the learning process.

The former educational paradigm based on the opinion that it is possible to determine an amount of knowledge sufficient for students' life activity and then transmit it to them reached its limits. Increase of scientific knowledge is reflected in the content of university training programs. The teacher remaining focused on knowledge transmission rather than equipping students with reliable algorithms of absorbing and evaluation of information raises standards to the amount of knowledge. Some attempts that teachers undertake to provide for various students' life styles lead to increase and complication of the learning material.

However, the main goal of higher education is to develop students' intelligence [13], not to fill them with information. Modern society needs for effective development of students' intelligence and high-quality formation of the innovative professionals [14]. Teaching and educational tasks are becoming more complex and the amount of learning information is increasing and, consequently, students are being overloaded and overworked. To solve this problem, the learning process should be optimized: achieving best possible student learning outcomes defined in terms of knowledge, skills and abilities, a required level of the inner action plan, spending less time, efforts and tools of teachers and learners to achieve the results.

Based on $\mathrm{Yu}$.K. Babansky works, contemporary researchers suggest new ways of optimization and methods of constructing innovative models of university learning process in the following directions: optimization of the university teacher's activity and introduction of innovations at the methodological, theoretical and applied levels; ensuring the quality of education from the standpoint of psychology; application of active teaching methods; electronic information-educational technologies, etc. [15, pp. 66-67].

Development of students' memory is another aspect of the optimization. Psychology of memory paid great attention to the problem of obtaining knowledge considering it the final result of learning and life experience [16]. L. Székely came to the conclusion that memorized, verbally expressed knowledge proved to be often inadequate, functionally inefficient [17]. Still, the scientist distinguishes information and knowledge but does not mention the terms. The number of researchers who use the notions of information and knowledge is constantly growing, thus proving the scientific functionality of this distinguishing.

Information is a linear (verbal information) or nonlinear (visual information) organized system of signs which transmits a message being perceived and identified by a receiver and corresponds to certain representations in the consciousness of both the receiver and sender. But if the information can be identified with a representation that arises from the perception of a chain of signs, knowledge is a system of transformed representations, a system of converting some representations into others. This system of representations reflects features of the object investigated and peculiarities of the person's activity undertaken to study the object. This activity is fixed in the categories and classifications that are used by the learner to identify the representations about the object. Therefore, the teacher transmits dual information: about the content of the message and about the way of processing informational representations into knowledge.

Reporting function of information can also be fulfilled with educational facilities, but its organizational function is performed only by a teacher [18, pp. 343-365]. Recoding of information into knowledge consists of several stages: 1) restructuring of old knowledge for the purpose of comprehending new information; 2) formation of new skills. Essentially, skills are a sort of external analogues of notions. Notions are based on generalization (transition from the specific to the general with the subsequent concretizing). Skills are also based on generalization as transfer of an action from one activity to another; 3) differentiation of new and old representations; 4) consequence from the representations formed. The final result of the inner (mental) transformations of representations evoked by the information perceived is getting knowledge as a system of interconnected notions. The notion itself acts as a system of representations transformation, transition of some representations into others that correspond to establishing the invariant-variant relationship between the objects of the activity they are involved in.

Let us have a look at the following scheme that gives a more detailed information:

\begin{tabular}{|l|}
\hline Information - representation \\
\hline Restructuring of old knowledge \\
\hline $\begin{array}{l}\text { Transforming old knowledge under the influence of new } \\
\text { information }\end{array}$ \\
\hline Differentiation of new and related representations \\
\hline Formation of a new skill \\
\hline Inference (consequence) of initial representations \\
\hline Knowledge (a system of representations transformed) \\
\hline
\end{tabular}




\section{Fig 1. Stages of transforming information into knowledge}

Information presented in a form of an oral or written text causes the recipient to have representations of certain types. Under the influence of these representations, new representations are compared with the similar or related ones that the recipient has in his experience. Transformation of the prior knowledge affected by new information is connected with correction, clarification and/or addition of existing knowledge with regard to new information. Characteristic features of information obtained are defined also at this stage. The stage of differentiating new and related representations presupposes conscious determination of information accuracy and relevancy, spheres and methods of its application. At the next stage, skills to apply new information in different satiations, including familiar and stereotyped ones, are formed. While forming the skills in question, the student decides if the information acquired is helpful and stores it in his memory in a form of his own knowledge, set of his intellectual operations and their result.

The process of information transformation needs consistent identification of information qualitative and quantitative characteristics: completeness, redundancy and insufficiency (amount of information in the text) and timeliness, relevance, accuracy, validity, etc. (characteristics of text information).

Taking into account qualitative and quantitative characteristics of information, consider the following detailed algorithm of students' actions to be taken to transform information into knowledge, with cognitive skills corresponding to each stage:

1. Perception of text information.

2. Identification of quantitative characteristics of information.

3. Insufficiency: Request for additional information Identification of presuppositions.

+ Acquiring additional information - - - making the text complete

3. a. Redundancy: eliminating unnecessary information by means of various compression techniques.

3. b. Completeness of information (sufficiency).

4. Logical text organization.

5. Identification of qualitative characteristics of information.

6. Predicting the meaning of the text.

7. Analyzing the text content.

8. Confirmation / rejection or correction of the hypothesis with regard to the communicative task and a speaker's psychological portrait .

9. Construction and checking variants for language expression of the information.

10. Drawing a supporting scheme with a necessary presupposition or constructing a counter-text that are inferred from the meaning of the information obtained.

Thus, construction of a supporting scheme or countertext goes through the following work stages:

- Determining the amount of information;

- Ensuring completeness of information;

- Logical organization of information;

- Identifying types of presuppositional data;
- Comparing presuppositions with the information content;

- Conclusion regarding information characteristics

The reverse process - representation of information, i.e. converting cognitive structures into speech structures - can be presented in the form of an algorithm:

1. Creation of a conception (thought) in an internal plan: intention - conception - conception structuring (its division into plots) - construction of speech structures analysis of representations constituting each speech situation.

2. Transformation of the representations using operations of converting internal speech structures into external speech: choosing the word, substitution, repetition, narrowing, extension, accentuation, transformation, combination.

3. Text building with regard to the nature of a thought (ambiguity, implication, figurativeness), information completeness (degree of completeness is assessed due to the communicative task and interlocutor's level), logic of presentation (deduction, induction, mixed).

4. Formulation of a communicative task in external speech: enquiry, message, inducement, persuasion, impressing.

5. Identification of means of expression (intonation, logical arrangement, imperative, etc.).

These didactic schemes require the teacher to correlate the information being presented with the knowledge the students have; to identify the specific features of education activities to form a skill as an actions transfer (or generalization); to determine the difference between old and new knowledge; to predict its further developing (conclusions).

From our point of view, this process is multistage. The first stage is connected with restructuring of the available knowledge under the influence of information. Let us consider types of cognitive skills that are being formed during the learning activity described.

\section{Types of cognitive skills and sources of their formation (content of teaching)}

Therefore, the structure of cognitive skills that are essential for successful cognitive activity is determined according to the student's ability to: identify and formulate the problem; generate as many ideas as possible; consider the real objects and phenomena from different points of view, avoid stereotyped models of their perception; generate diverse ideas; creatively respond to stimuli; improve the object adding some details; solve problems, i.e. analyze and synthesize; think divergently while making decisions, see multiple possible solutions, think imaginatively (including atypical situations); etc.

Cognitive skills are formed by means of such verbalcogitative operations as denotative and predicative, complex and logical text analysis, text predicting, text planning, identification of presuppositions, varied presentation of a text, identification of presuppositions of different types, psychological profiling of the text producer, self-reflection of the target addressee [19, 20]. 
The notions described above serve as a basis for selecting the content of language learning and organization of studying the learning material. To provide the cognition of the language learning is only possible when theoretical knowledge of different sciences that deal with the language and person's speech activity is taken into account: Linguistic, Psycholinguistics, Information theory, Logic, Theory of communication.

\section{Developing a strategy for students' work with learning material}

Building a system of tasks for developing students' cognitive skills presupposes:

- $\quad$ selecting basic topics (text structure; denotative and predicative lexical categories; external and internal lexical relations) to systematically present the content and objectives of teaching;

- $\quad$ considering relationships between language/speech and mental categories (representations) in the process of text perception and construction to provide working the mechanisms of information interiorization and exteriorization;

- formation of communicative competence as a theoretical base for successful work with text information; - formation and improvement of skills to work with text information by recursive presentation of the material, regular generalizations, demonstration of stages of transforming information into knowledge;

- $\quad$ taking into account meaning and sense of language units and their combinations in a text, level text organization, defining specific features of semantics by making a distinction between inner and external speech, classification of the vocabulary according to denotations and predicates, dividing lexical relations into internal and external ones make students realize the connection between semasiology and text production, how to match mental and speech/language categories, self-reflect on using algorithms of work on the text.

Cognitive skills and abilities of students to work with information independently (such as search, selection, classification, formalization of information structures) are directly connected and clearly correlated with the skills listed above. If students' cognitive activity is organized in the following way, it facilitates comprehension and extraction of information to be applied and creatively processed:

- $\quad$ students are offered a model for comprehension and extraction of specific information, with this model based on communication goals and used as a support for learning students to include the information into their monologues;

- $\quad$ specific features of semantic perception and comprehension of the information performed for a definite communication goal are considered in the learning process;

- $\quad$ this mental work is reinforced with speech actions;

- results of verbal-cogitative activity are used to make up a plan of a potential utterance which serves as an information basis of the activity;
- $\quad$ student texts are selected and didactically organized with due regard to the communicative significant information and appropriate vocabulary (general scientific, special, terminological);

- $\quad$ speech skills and exercises and cognitivecommunication tasks, and also simulations are grouped and substantiated.

The authors of the present article decided to experimentally test the following assumptions:

- $\quad$ skill to define amount and characteristics of text information will be formed and successfully improved if students are provided with such a theory that completely and accurately describes qualitative and quantitative characteristics of information according to a algorithm of their identification;

- a cognitive skill to transform external information into internal knowledge can be formed if students are given an algorithm of transformation of text information into structures of universal subject codes by means of constructing a supporting logical scheme;

- a cognitive skill to determine the logic of presenting the information can be formed if logical and linguistic categories are correlated, with genus-species, part-towhole, and equivalence-association (hyponymy, heteronymy, synonymy, referential metonymy) relations being the main ones;

- a cognitive skill of variative text construction can be successfully formed if students get information about such operations of transforming mental structures into external speech as combination, transformation, substitution, narrowing and extension of the meaning and some others;

- a cognitive skill to reconstruct a text using presuppositional data can be formed if students are offered information about different types of presuppositions and ways of their detection.

To test the hypothesis stated above, the following objectives of the experiment were set:

- to include the topics "Information and knowledge", "Informational processes", "Qualitative and quantitative characteristics of information" into the content of teaching (it should be noted that some linguistic courses do have these issues but they include different aspects and, as for the theory, it is not clearly organized to reach our goals);

- to compress theoretical material into systems of supporting schemes (the teacher, thereby, gives an example of studying and transformation of the information into the inner speech), thus demonstrating variative decompression of these schemes into a text that contributes to a large extent to making sense of the information and converting it into long-term memory;

- to offer the students of the experimental groups a system of tasks aimed at forming and developing cognitive skills;

- to substantiate the strategy for students' work with learning material and do it in a form of an algorithm [21].

Monitoring of the learning process of the experimental base (307 freshmen and sophomores of the Siberian State Automobile and Highway University) let us establish the fact that the level of students' cognitive skills 
development does not correspond to the level of the requirements for the students and the graduates. To diagnose the degree of cognitive skills development, the participants were given a text to work with. The data obtained (312 answers selected at random were analysed) revealed the following weak points: wrong word selection $(76 \%)$, word repetition in a short piece of text $(69 \%)$, wrong collocations $(43 \%)$, wrong interpretation of the unit $(55 \%)$, errors of style and definition structures, identical cohesive devices and groundlessness of their usage $(87 \%)$, fallible narrative logic $(59 \%)$, insufficiency or redundancy of information in the text $(63 \%)$, misuse of words in the given context (48\%), lack of speech variation (93\%); difficulties with constructing definitions (71\%), with changing the text logic $(49 \%)$, problems with conscious performance of intellectual operations (98\%), constructing a text without drawing a clear plan (67\%), etc.

Students experience serious difficulties in recalling the theory. An ascertaining experiment revealed that the students are not good enough at text production, using good grammar and logic while speaking.

We identified the reasons of the problems listed above: poor vocabulary, underdevelopment of logical thinking, ignoring syntagmatic connectivity. The answers were brief that can be explained by the fact that $69 \%$ of the students did not want to complete the tasks they had been given, $77 \%$ of the participants were not able to do them, and $84 \%$ of the students did not have appropriate knowledge. Therefore, conscious efforts should be made to overcome these difficulties.

A system of learning tasks developed for the students of the experimental groups included: analyzing notions in the text and identifying their logical relations with their presentation in a scheme; estimating the amount of text information, discovering and eliminating information redundancy; drawing logical conclusions concerning the completeness of information and addition of its missing elements if necessary; identifying text presuppositions and making decisions on their embedding into the text. When students identify presuppositions, the following cognitive skills are being formed: to compare language expression and mental invariant; understand the difference between the variants; identify and change the logic of counter-text presentation; think divergently while finding and making decisions, see multiple possible solutions, think imaginatively; recode information (convert information on the basis of semantic links); consider phenomena form different points of view, avoid stereotyped models of their perception, discover new ways of its practical application, self-control the logic of mental activity. All these kinds of work are connected with defining the semantics of lexemes, their combinations, relationships in the language and text, semantic links between information and reality (presuppositions), drawing conclusions and summarizing, text reconstruction on the basis of semantic transformations.
Middle assessment of the students showed a tendency to increasing the use of linguistic means in students' papers. The students aspired to acquire a skill of constructing and studying texts and their variative representation. Moreover, the students studiously avoid using redundant words and identify the completeness of the information clearly enough, giving explanations, if necessary. Motivation to acquiring means and ways of studying, enrichment and construction of a text is increased, in comparison with the first stage of work. Being actively involved in work on texts according to the algorithms, students discover various and even unexpected presuppositions.

The final stage of the experiment was devoted to: 1) assessment of students' work on the text; 2) diagnostics of development of students' verbal-cogitative activity.

The following tasks were offered to the students:

- to transform information into knowledge, show practical importance of the knowledge obtained;

- to construct supporting schemes for a text with compressing the information, it logical arrangement, revealing and adding missing elements, identifying presuppositions;

- to describe all the stages of the work done and the mental operations performed;

- $\quad$ to present the information in various ways.

We found that the students of the experimental groups actively used supporting schemes, efficient means of information compression, searched for presuppositions, correlated information with the existing knowledge. The information obtained by the students underwent serious cognitive processing: schematization, summarization, generalization, establishing cause-and-effect relations; finding logic bridges between problems, looking at the problem from different points of view, comparing them; drawing the proper conclusions and check them; performing appropriate mental operations while studying the text; identifying logic relations between presuppositions; defining the main and secondary; finding logical relation between notions; identifying and eliminating redundancy of information; finding associations, equivalents, establishing intergroup relations, categorization, systematization, generalization and classification, serial text organization; information compressing. Students demonstrated reflexive skills: analyzing the activity and its results while forming propositions; controlling the logic of their mental activity.

The number of students who could enumerate the set of operations necessary for successful work on the text information increased. At the beginning, there were $16 \%$ (only $5 \%$ of students enumerated them completely and it was produced from the perspective of external text characteristics. The results of the analysis of mental operations used by the students at the end of the experiment are given in table 1 .

Table 1. Mental operation performed and characteristics of oral answers given by the students of control and experimental groups while their studying the learning material (the beginning of study is the final assessment), \% 


\begin{tabular}{|l|c|c|c|c|}
\hline Mental operations performed to process text information & $\begin{array}{l}\text { Cont. Gr. } \\
\text { (begin.) }\end{array}$ & $\begin{array}{l}\text { Cont. Gr. } \\
\text { (end) }\end{array}$ & $\begin{array}{l}\text { Exp. Gr. } \\
\text { (begin.) }\end{array}$ & $\begin{array}{l}\text { Exp. Gr. } \\
\text { (end) }\end{array}$ \\
\hline Key points, mnemic aspect & 20 & 37 & 20 & 90 \\
\hline $\begin{array}{l}\text { Classification (distribution of subjects, phenomena, notions for classes, } \\
\text { groups on the basis of common features) }\end{array}$ & 10 & 12 & 10 & 80 \\
\hline Grouping (dividing the material into groups on any basis) & 10 & 10 & 11 & 78 \\
\hline Structuring (positioning of parts relative to each other) & 15 & 16 & 14 & 93 \\
\hline $\begin{array}{l}\text { Systematization (ordering in positioning of parts of the whole and their } \\
\text { connections) }\end{array}$ & 7 & 9 & 8 & 89 \\
\hline $\begin{array}{l}\text { Analogy (determination of similarity, resemblance in certain relations } \\
\text { between different subjects, phenomena) }\end{array}$ & 6 & 8 & 5 & 92 \\
\hline $\begin{array}{l}\text { Association (linking of the material to be memorized with the indiv. } \\
\text { experience of a person, based on similarity, contiguity or contradiction) }\end{array}$ & 10 & 10 & 9 & 85 \\
\hline Schematization (presenting the information in general); & 9 & 11 & 8 & 88 \\
\hline Seriation (information sorting in order according to its size, time, etc.) & 8 & 9 & 8 & 71 \\
\hline Recoding (information transformation based on the semantic links); & 7 & 7 & 7 & 90 \\
\hline Completing the material to be memorized (countertext) & 2 & 3 & 2 & 70 \\
\hline Text variability & 4 & 7 & 3 & 78 \\
\hline Conscious performance of mental operations & 3 & 4 & 4 & 92 \\
\hline
\end{tabular}

Thus, at the end of the formative experiment, we could state the following facts concerning formation and improvement of students' cognitive skills in experimental groups: the students not only present significant information while making notes but do it in a comprehensible and easy to decode way that testifies their conscious ability to transform information into knowledge; the students are embracing efficient methods of compressing information into supporting schemes; they self-control their intellectual activity.

According to the findings, students of the experimental groups were able to study more learning material presented in a form of a text in the same period. The same criteria were used to assess students' oral answers: quantitative assessment (marks) and qualitative assessment.

\section{Conclusion}

The work on formation and development of students' cognitive skills has the following results:

- it constantly increases students' motivation, develops their emotional environment, corresponds to the age-specific value and orientation activity, creates conditions for their autonomy;

- it helps to exercise self-control, leads to rapid mastering and using the material both in the learning process and extra-curricular activities;

- it makes possible to realize a combination of the communicative and information approaches in all kinds of speech and mental activities (actions for building a written speech are the leading ones);

- it provides the most favourable conditions for effective language acquisition;

- $\quad$ it is a means of realizing the principle of awareness and outliving that ensures the development of language competence.

\section{References}

1. A.V. Ruchina, M.V. Kuimova, D.A. Polyushko, A.E. Sentsov, Zhang Xue. Procedia Soc Behav Scis, 215, 98-101, (2015)

2. V. Jackson, Current Issues in Education, 19, issue 2, $1-35,(2016)$

3. S.M. Wechsler et al. Thinking Skills and Creativity, 27, 114-122 (2018)

4. N.A. Kovalenko, A.Yu. Smirnova, Procedia Soc Behav Scis, 166, 393 - 398 (2015)

5. G.J. Harfitt, M. L. Ch. Jessie, Teaching and Teacher Education, 73, 120-129 (2018)

6. E. Aizikovitsh-Udi, M. Amit, Procedia Soc Behav Scis, 15, 1087-1091 (2011)

7. V. P. Glăveanu, L. Tanggaard, New Ideas in Psychology, 34, 12-21 (2014)

8. C. Richardson, P. Mishra Thinking Skills and Creativity, 27, 45-54 (2018)

9. E. Ziegler, M. Kapur Thinking Skills and Creativity, 30, 64-75, (2018)

10. G. J. Harfitt, J.M.L. Chow, Teaching and Teacher Education, 73, 120-129 (2018)

11. Y. Kirkgöz, Procedia Soc Behav Scis, 158, 394-401 (2014)

12. Chih-Yung Tsai, Ya-Han Chang, Chia-Lun Lo, Thinking Skills and Creativity, 27, 55-63 (2018)

13. M.A. Kholodnaya, E.V. Volkova, Procedia Soc Behav Scis, 217, 914-922 (2016)

14. I. Belski, R. Adunkab, O. Mayerc Procedia CIRP, 39, $79-84$ (2016)

15. Yu.K. Babansky, M.N. Ptashnik (V voprosakh i otvetakh) [Electronic linguodidactics]. (Rad. shkola, Kiev, 1982) (in Russian)

16. Ch. Hughes, J. Costley, Ch. Lange Interactive Technology and Smart Education, 15, issue 3, 220237 (2018)

\footnotetext{
*Corresponding author: sidorova ma79@mail.ru
} 
17. L. Székely The Psychology of Thinking (Progress Publ., Moscow, 1965)

18. E.V. Tsoupikova, Development of skills of recognizing and neutralizing manipulative impact: logic and psychosemantic aspects of text information perception (Omsk, SibADI, 2012)
19. V. P. Glăveanu, Thinking Skills and Creativity, 27, 25-32 (2018)

20. A.M. Klyoster, G.G. Galich, Procedia Soc Behav Scis, 206, 56-61 (2015)

21. M.V. Tsyguleva, H.V. Tsoupikova, M.A. Fedorova, I.N. Efimenko, Advances in Intelligent Systems and Computing 907 (2019) 